\title{
Relationship Between HbAlc and Complex Regional Pain Syndrome in Stroke Patients With Type 2 Diabetes Mellitus
}

\author{
Jong Ho Choi, MD, Ki Pi Yu, MD, PhD, Yong-Soon Yoon, MD, PhD, Eun Sil Kim, MD, Ji Hyun Jeon, MD
}

Department of Rehabilitation Medicine, Presbyterian Medical Center, Seonam University College of Medicine, Jeonju, Korea

Objective To investigate the relationship between glycosylated hemoglobin A (HbAlc) and complex regional pain syndrome (CRPS) in stroke patients with type 2 diabetes mellitus (T2DM).

Methods A retrospective chart review was performed of stroke patients from January 2012 to December 2013. We reviewed 331 patients and included 200 in the analysis. We divided them into CRPS and non-CRPS groups and compared them by age, gender, stroke lesion, cause of stroke, duration of T2DM, HbAlc (\%), National Institutes of Health Stroke Scale score, affected shoulder flexor muscle strength, Fugl-Meyer Assessment score, motricity index, Functional Independence Measure, Korean version of Modified Barthel Index, blood glucose level on admission day, duration from stroke onset to HbAlc check, and duration from stroke onset to three-phase bone scan for CRPS diagnosis. Thereafter, we classified the patients into five groups by HbAlc level (group 1, 5.0\%-5.9\%; group 2, 6.0\%-6.9\%; group 3, 7.0\%-7.9\%; group 4, 8.0\%-8.9\%; and group 5, 9.0\%-9.9\%) and we investigated the difference in CRPS prevalence between the two groups.

Results Of the 200 patients, 108 were in the CRPS group and 92 were in the non-CRPS group. There were significant differences in HbAlc $(\mathrm{p}<0.05)$ between the two groups but no significant differences in any other factors. Across the five HbAlc groups, there were significant differences in CRPS prevalence $(\mathrm{p}<0.01)$; specifically, it increased as HbAlc increased.

Conclusion This study suggests that higher HbAlc relates to higher CRPS prevalence and thus that uncontrolled blood glucose can affect CRPS occurrence in stroke patients with diabetes.

Keywords Glycosylated hemoglobin A, Complex regional pain syndromes, Diabetes mellitus, Stroke

Received August 24, 2015; Accepted February 1, 2016

Corresponding author: Ki Pi Yu

Department of Rehabilitation Medicine, Presbyterian Medical Center, Seonam University College of Medicine, 365 Seowon-ro, Wansan-gu, Jeonju 54987, Korea. Tel: +82-63-230-1460, Fax: +82-63-285-3385, E-mail: withjoy9@naver.com

ORCID: Jong Ho Choi (http://orcid.org/0000-0002-1048-6361); Ki Pi Yu (http://orcid.org/0000-0002-6597-5840); Yong-Soon Yoon (http://orcid. org/0000-0003-4709-3964); Eun Sil Kim (http://orcid.org/0000-0003-1996-4451); Ji Hyun Jeon (http://orcid.org/0000-0001-5666-1260).

(c) This is an open-access article distributed under the terms of the Creative Commons Attribution Non-Commercial License (http://creativecommons.org/ licenses/by-nc/4.0) which permits unrestricted noncommercial use, distribution, and reproduction in any medium, provided the original work is properly cited. Copyright $\odot 2016$ by Korean Academy of Rehabilitation Medicine 


\section{INTRODUCTION}

Complex regional pain syndrome (CRPS) is characterized by disproportionate pain, allodynia, vasomotor changes, decreased range of motion, hyperalgesia, edema, and skin temperature or color change [1]. In the past, it was called reflux sympathetic dystrophy in acknowledgement that it was primarily an abnormal sympathetic nervous reflex that was involved. However, both sympathetically maintained pain and sympathetically independent pain have been found to exist, and thus the name was ultimately changed to CRPS by the International Association for the Study of Pain (IASP) in 1994. CRPS is divided into type I and type II by absence or presence of peripheral nerve injury $[1,2]$; type II generally occurs more frequently, but type I occurs more frequently in stroke patients [3].

CRPS occurs in the affected limbs of stroke patients in the recovery phase. Prevalence differs widely according to diagnostic standards and methods [4] and has been reported to vary from $12.5 \%$ to $70 \%$ depending on clinical signs and symptoms $[5,6]$. CRPS onset time is known to be from 1 to 5 months after stroke, and if it is not treated properly, there is a high possibility of irreversible change [4].

The pathophysiology of CRPS is unclear, but it is usually considered a multifactorial disease with clinical features that range from abnormal reflection to tissue damage causes such as neurogenic inflammation, nociceptive sensitization, vasomotor dysfunction, and maladaptive neuroplasticity [7].

Diabetes mellitus (DM) is a multisystem disease characterized by persistent hyperglycemia that has both acute and chronic biochemical and anatomical sequelae [8]. Glycosylated hemoglobin A (HbAlc) is an index of blood glucose control, and it reflects the average blood glucose level for 2 to 3 months $[9,10]$. Normal HbAlc is below $6 \%$, but it exceeds $6 \%$ in diabetes and can increase up to $10 \%-12 \%$ [11].

A number of studies have reported that CRPS is one of the musculoskeletal complications in patients with DM $[8,12,13]$, but there are no studies on the relationship between HbAlc and CRPS prevalence. Thus, the purpose of this study was to investigate the relationship between HbAlc and CRPS prevalence in stroke patients with diabetes and to understand how uncontrolled hyperglyce- mia can affect CRPS occurrence in these patients.

\section{MATERIALS AND METHODS}

\section{Subjects}

We retrospectively reviewed the medical records of 331 patients who had been admitted to Jesus Hospital (Presbyterian Medical Center) from January 2012 to December 2013. The inclusion criteria for the study were (1) stroke confirmed through either cerebral infarction or cerebral hemorrhage and (2) a diagnosis of diabetes. The following were the exclusion criteria for this study: history of injury in an upper extremity, hyperthyroidism, hyperparathyroidism, peripheral neuropathy (including from diabetes), or previous CRPS.

\section{Methods}

\section{Diagnosis of CRPS}

The patients were diagnosed using the IASP's proposed revised CRPS clinical diagnostic criteria [14] and diagnosed by a physician in the Department of Nuclear Medicine based on a three-phase bone scan (TPBS) [15]. We divided the patients into two groups, with or without CRPS, and compared them by age, gender, stroke lesion, DM duration, HbAlc (\%), National Institutes of Health Stroke Scale (NIHSS) score, affected shoulder flexor muscle strength, Fugl-Meyer Assessment (FMA) score, motricity index (MI), Functional Independence Measure (FIM), Korean version of Modified Barthel Index (K-MBI) score, blood glucose level on admission day, duration from stroke onset to HbAlc check, and duration from

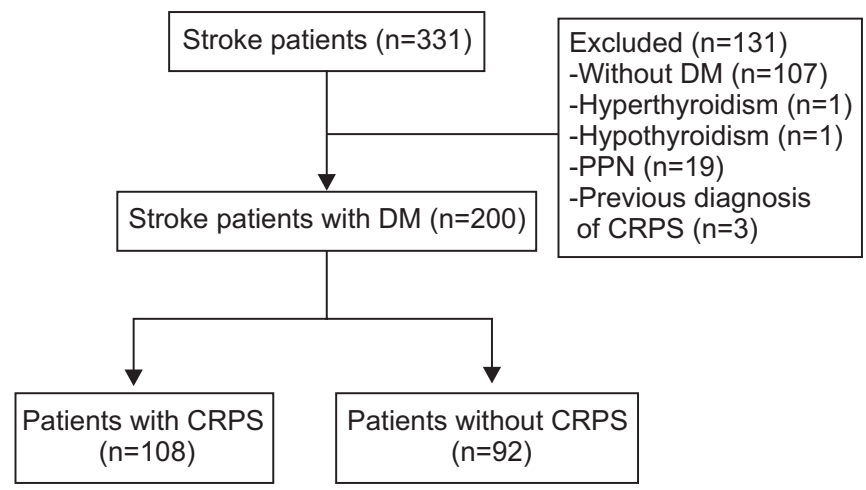

Fig. 1. Flow diagram of patients included in this study by CRPS versus non-CRPS groups. DM, diabetes mellitus; CRPS, complex regional pain syndrome; PPN, peripheral polyneuropathy. 


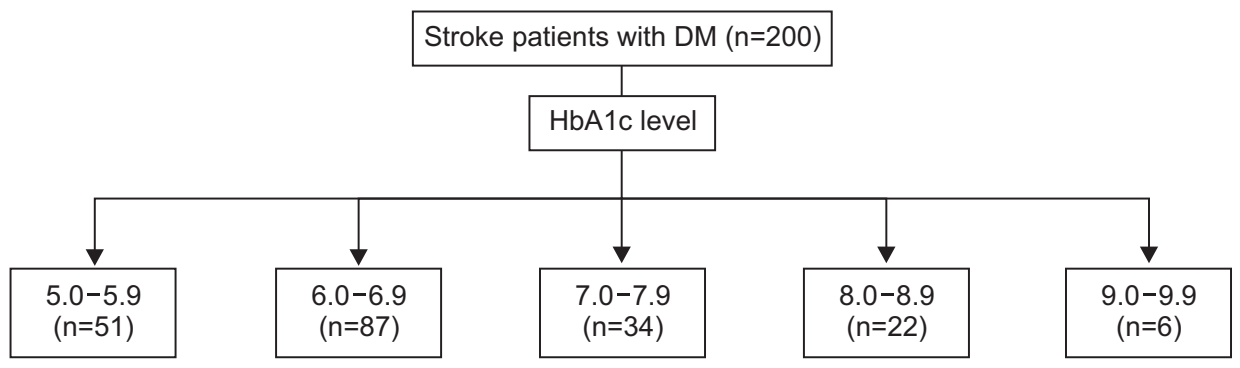

Fig. 2. Flow diagram of the five HbAlc groups. DM, diabetes mellitus; HbAlc, glycosylated hemoglobin A.

stroke onset to the TPBS for CRPS diagnosis (Fig. 1).

\section{HbAlc}

Among the 200 stroke patients with DM, we classified them into five groups by HbAlc value: group 1, 5.0\%$5.9 \%$; group $2,6.0 \%-6.9 \%$; group $3,7.0 \%-7.9 \%$; group 4 , 8.0\%-8.9\%; and group 5, 9.0\%-9.9\%. Specifically, we compared the CRPS prevalence in each HbAlc group (Fig. 2).

\section{Statistical analysis}

Statistical analyses were performed using SPSS ver. 20.0 (IBM SPSS Inc., Armonk, NY, USA). We conducted independent $\mathrm{t}$-tests to compare the CRPS and non-CRPS groups and chi-squared tests to compare CRPS prevalence in the five $\mathrm{HbAlC}$ groups. Statistical significance was set at $\mathrm{p}<0.05$ for both sets of tests.

\section{RESULTS}

We analyzed the data from a total of 200 stroke patients with DM, 130 males and 70 females; mean patient age was $68.84 \pm 10.32$ years. The patients comprised 136 with cerebral infarction and 64 with hemorrhagic stroke; mean DM duration was $47 \pm 17.3$ months and mean HbAlc was $6.68 \pm 0.97 \%$ (Table 1 ).

One hundred eight of the 200 subjects were diagnosed with CRPS, with the remaining 92 comprising the nonCRPS group. There were significant differences in HbAlc $(\mathrm{p}<0.05)$ but no significant differences between the CRPS groups in age, gender, stroke lesion, cause of stroke, DM duration, NIHSS score, affected shoulder flexor muscle strength, FMA score, MI, FIM, K-MBI score, blood glucose level duration from stroke onset to HbAlc check, or duration from stroke onset to the TPBS for CRPS diagnosis ( $\mathrm{p}>0.05)$ (Table 2).

By HbAlc level, CRPS prevalence differed significantly ( $<<0.01$ )—group 1, 33\%; group $2,51 \%$; group $3,76 \%$; group 4, 68.18\%; and group 5, 83.33\% (Table 3); that is, as HbAlc
Table 1. General characteristics of subjects $(n=200)$

\begin{tabular}{|cc|}
\hline Characteristic & Value \\
\hline Age (yr) & $68.84 \pm 10.32$ \\
\hline Gender & 130 \\
\hline Male & 70 \\
\hline Female & \\
\hline Cause of stroke & 136 \\
\hline Infarction & 64 \\
\hline Hemorrhage & $47 \pm 17.3$ \\
\hline Duration of DM (mo) & $6.68 \pm 0.97$ \\
\hline HbAlc (\%) & \\
\hline Stroke lesion side & 122 \\
\hline Rt. hemisphere & 78 \\
\hline Lt. hemisphere & \\
\hline Stroke lesion & 86 \\
\hline Cortex & 101 \\
\hline Subcortex & 13 \\
\hline Brainstem & \\
\hline
\end{tabular}

Values are presented as mean \pm standard deviation or number of subjects.

DM, diabetes mellitus; HbAlc, glycosylated hemoglobin A.

increased, CRPS prevalence increased as well (Fig. 3).

\section{DISCUSSION}

DM is considered highly related to CRPS occurrence $[8,12,13]$, and thus we attempted to investigate how uncontrolled hyperglycemia can affect CRPS occurrence in stroke patients with diabetes by analyzing the relationship between HbAlc and CRPS prevalence in these patients. In this study, as HbAlc values increased, CRPS prevalence increased as well, and thus we consider that maintaining adequate blood glucose levels is important for reducing CRPS occurrence in stroke patients with diabetes.

CRPS is characterized by severe pain, allodynia, hyper- 
Table 2. Comparisons between the CPRS and non-CRPS groups

\begin{tabular}{|c|c|c|c|}
\hline & $\begin{array}{c}\text { CRPS group } \\
(\mathbf{n}=108)\end{array}$ & $\begin{array}{c}\text { Non-CRPS group } \\
(\mathrm{n}=92)\end{array}$ & p-value \\
\hline Age (yr) & $68.75 \pm 9.83$ & $68.92 \pm 10.77$ & $0.50^{\mathrm{b})}$ \\
\hline Gender & & & $0.72^{\text {a) }}$ \\
\hline Male & 61 & 69 & \\
\hline Female & 31 & 39 & \\
\hline Stroke lesion & & & $0.15^{\mathrm{a})}$ \\
\hline Cortex & 38 & 48 & \\
\hline Subcortex & 51 & 50 & \\
\hline Brainstem & 3 & 10 & \\
\hline Cause of stroke & & & $0.45^{\mathrm{a})}$ \\
\hline Infarction & 67 & 69 & \\
\hline Hemorrhage & 25 & 39 & \\
\hline Duration of DM (mo) & $4.11 \pm 2.85$ & $3.53 \pm 2.17$ & $0.10^{\mathrm{b})}$ \\
\hline $\operatorname{HbAlc}(\%)$ & $6.92 \pm 0.99$ & $6.39 \pm 0.86$ & $0.001^{\mathrm{b})}$ \\
\hline NIHSS & $10.99 \pm 4.69$ & $11.38 \pm 4.25$ & $0.53^{\mathrm{b})}$ \\
\hline Affected shoulder flexor muscle strength (MRC) & $0.68 \pm 0.67$ & $0.68 \pm 0.68$ & $0.92^{b)}$ \\
\hline FMA & $4.34 \pm 7.60$ & $5.76 \pm 9.90$ & $0.26^{\mathrm{b})}$ \\
\hline MI & $19.24 \pm 18.01$ & $21.81 \pm 18.96$ & $0.32^{b)}$ \\
\hline FIM & $57.41 \pm 23.09$ & $54.36 \pm 23.54$ & $0.22^{\mathrm{b})}$ \\
\hline K-MBI & $36.99 \pm 22.30$ & $35.80 \pm 22.76$ & $0.71^{\mathrm{b})}$ \\
\hline Blood glucose level on admission day & $141.76 \pm 39.39$ & $151.59 \pm 34.36$ & $0.06^{\mathrm{b})}$ \\
\hline Duration from stroke onset to HbAlc check (day) & $49.31 \pm 43.35$ & $55.84 \pm 45.03$ & $0.29^{b)}$ \\
\hline $\begin{array}{l}\text { Duration from stroke onset to check } \\
\text { TPBS for diagnosis of CRPS (day) }\end{array}$ & $66.22 \pm 41.90$ & $71.09 \pm 32.56$ & $0.36^{\mathrm{b})}$ \\
\hline
\end{tabular}

Values are presented as mean \pm standard deviation or number of subjects.

DM, diabetes mellitus; HbAlc, glycosylated hemoglobin A; NIHSS, National Institutes of Health Stroke Scale; MRC, Medical Research Council; FMA, Fugl-Meyer Assessment scale; MI, motricity index; FIM, Functional Independence Measure; K-MBI, Korean version of Modified Barthel Index; TPBS, three-phase bone scan; CRPS, complex regional pain syndrome.

Statistically significant as $\mathrm{p}<0.05 .{ }^{\mathrm{a})} \mathrm{Chi}$-square test, ${ }^{\mathrm{b})}$ independent t-test.

algesia, and motor and autonomic signs and symptoms [7]. With regard to the pain itself, Calder et al. [16] and Van der Laan and Goris [17] reported that inflammatory response is the primary pain mechanism in CRPS patients. In addition, the activation of skin nociceptor that we can see in these patients induces retrograde depolarization of primary afferent nerves with small diameters, increasing the secretion of neuropeptides such as substance $\mathrm{P}$ and calcitonin gene-related peptide (CGRP) in the sensory endings of the skin [18]. These neuropeptides evoke vasodilatation and protein extravasations in the tissue, and the resulting signs such as reddening, warming, and edema are called neurogenic inflammation [18]; most inflammatory changes from CRPS are mediated by CGRP and substance P. Serum concentrations of both of these substances are higher in CRPS patients than in healthy control individuals $[19,20]$.

The concentrations of cytokines also show differences. In skin biopsy results, the concentrations of tumor necrosis factor-alpha (TNF- $\alpha$ ) and interleukin-6 (IL-6) were much higher in upper extremities affected by CRPS than in normal upper extremities $[21,22]$. In early-stage CRPS (3 months on average), water-soluble TNF receptor and pro-inflammatory cytokines (TNF), IL-1, and IL-8 increased in blood serum whereas anti-inflammatory cytokines (IL-4, IL-10, and transforming growth factor- 
Table 3. Correlations between CRPS prevalence, age, DM duration, affected shoulder flexor muscle strength, stroke lesion, and stroke cause by HbAlc

\begin{tabular}{|c|c|c|c|c|c|c|}
\hline & $\begin{array}{l}\text { Group1 } \\
(n=51)\end{array}$ & $\begin{array}{c}\text { Group 2 } \\
(n=87)\end{array}$ & $\begin{array}{c}\text { Group } 3 \\
(n=34)\end{array}$ & $\begin{array}{c}\text { Group } 4 \\
(n=22)\end{array}$ & $\begin{array}{c}\text { Group } 5 \\
(n=6)\end{array}$ & p-value \\
\hline CRPS patients & 17 & 45 & 26 & 15 & 5 & \\
\hline CRPS prevalence (\%) & 33.33 & 51.72 & 76.47 & 68.18 & 83.33 & $0.001^{*}$ \\
\hline Duration of DM (mo) & $43 \pm 30.5$ & $45 \pm 27.6$ & $48 \pm 33.8$ & $48 \pm 34.1$ & $54 \pm 50.9$ & 0.837 \\
\hline $\begin{array}{l}\text { Affected shoulder flexor } \\
\text { muscle strength (MRC) }\end{array}$ & $0.9 \pm 0.7$ & $0.6 \pm 0.6$ & $0.6 \pm 0.7$ & $0.5 \pm 0.7$ & $1 \pm 0.9$ & 0.052 \\
\hline Stroke lesion & & & & & & 0.595 \\
\hline Cortex & 22 & 39 & 13 & 9 & 3 & \\
\hline Subcortex & 28 & 43 & 16 & 11 & 3 & \\
\hline Brainstem & 1 & 5 & 5 & 2 & 0 & \\
\hline Cause of strokes & & & & & & 0.468 \\
\hline Infarction & 31 & 63 & 25 & 14 & 3 & \\
\hline Hemorrhage & 20 & 24 & 9 & 8 & 3 & \\
\hline
\end{tabular}

Values are presented as number of subjects or mean \pm standard deviation.

CRPS, complex regional pain syndrome; MRC, Medical Research Council; FMA, Fugl-Meyer Assessment scale; MI, motricity index; NIHSS, National Institutes of Health Stroke Scale score; FIM, Functional Independence Measure; KMBI, Korean version of Modified Barthel Index.

HbAlc level: group 1, 5.0\%-5.9\%; group 2, 6.0\%-6.9\%, group 3, 7.0\%-7.9\%; group 4, 8.0\%-8.9\%; group 5, 9.0\%-9.9\%. ${ }^{*} \mathrm{p}<0.05$ by chi-square test.

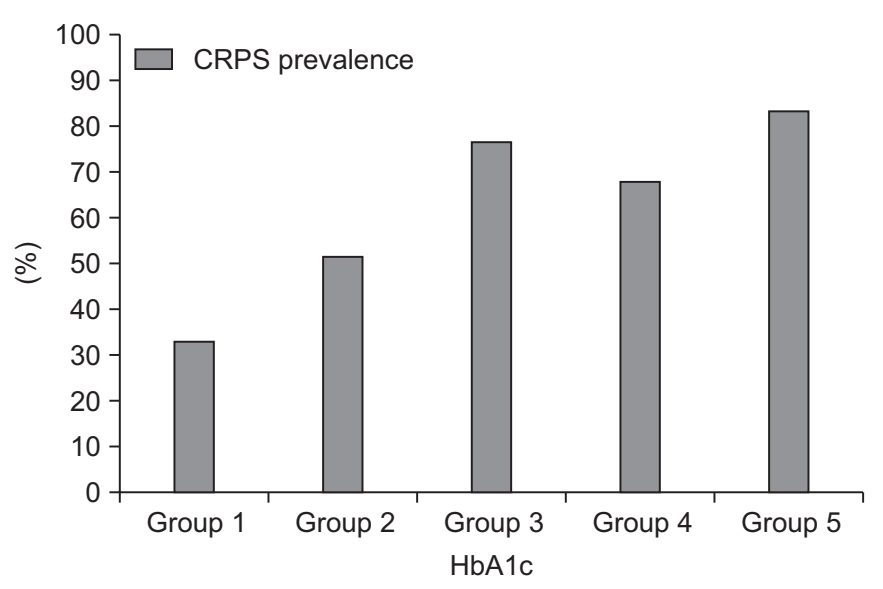

Fig. 3. CRPS prevalence by HbAlc; as HbAlc increased, CRPS prevalence increased. CRPS, complex regional pain syndrome; HbAlc, glycosylated hemoglobin A.

betal [TGF- $\beta 1]$ ) decreased $[23,24]$. It was reported that these pro-inflammatory cytokines caused sensitization and hyperalgesia [25], which indicates that neurological inflammatory response plays an important role in the occurrence of CRPS.

Type 2 diabetes mellitus (T2DM) is an inflammatory disorder that develops when there is a pathologic problem in the immune system [26], and it features high blood concentrations of congenital immune mediators due to the occurrence of pathologic consequences $[9,27]$. It has been reported that compared with control groups, the serum levels of pro-inflammatory cytokines (IL-1 $\beta$, IL-6 and TNF- $\alpha$ ), sialic acid and C-reactive protein, and malondialdehyde were significantly higher in T2DM patients [9,26-33]. As glycemic control in these patients worsens (HbAlc $>6.5 \%$ ), serum TNF- $\alpha$ appears to increase proportionally [28].

These secretions of pro-inflammatory cytokines in diabetes play an important role and could be associated with neurogenic inflammation and vasomotor dysfunction in CRPS. Classically, CRPS is subdivided into three phases (acute, atrophic, and dystrophic). Among these, the primary acute inflammatory phase can last for weeks up to 6 months and is characterized by painful range of motion, edema, warmth, and erythema of the hand and wrist [34-37]. Therefore, we consider that worsening glycemic control is associated with the acute inflammatory phase of CRPS.

According to the result of this study, the higher the HbAlc in stroke patients with diabetes, the higher their CRPS prevalence. HbAlc values reflect hyperglycemia, during which pro-inflammatory cytokines and acute- 
phase reactive proteins increase, resulting in increased neuroinflammatory reactions and CRPS.

However, our study was limited by a number of important factors. The study was cross-sectional and thus it was limited to inferring causal relationships. Second, shoulder joint subluxation, which is known a factor in CRPS occurrence, was not included in the study; instead we substituted shoulder muscle flexor strength and motricity index, neither of which controlled for the shoulder subluxation. Finally, the number of CRPS patients was small for the comparison between CRPS prevalence and HbAlc. These limitations suggest possible directions for future study. Furthermore, long-term follow-up research on the relationship between decreased HbAlc and improved CRPS is considered necessary. Then, we can suggest physiological grounds for any causal relationships between blood glucose level and CRPS through studies about improved CRPS symptoms or reduced absorption ratio on TPBS with lower HbAlc.

In this study, we concluded that uncontrolled hyperglycemia is related to CRPS occurrence in stroke patients with DM by comparing their HbAlc values with their CRPS prevalence; because CRPS prevalence increased as HbAlc increased, we considered that uncontrolled hyperglycemia affects CRPS occurrence. Therefore, it is necessary to maintain adequate blood glucose control in stroke patients with diabetes in addition to providing range of motion exercises and medical, physical, and occupational therapy.

\section{CONFLICT OF INTEREST}

No potential conflict of interest relevant to this article is reported.

\section{REFERENCES}

1. Stanton-Hicks M, Janig W, Hassenbusch S, Haddox JD, Boas R, Wilson P. Reflex sympathetic dystrophy: changing concepts and taxonomy. Pain 1995;63:12733.

2. Merskey H, Bogduk N. Classification of chronic pain: descriptions of chronic pain syndromes and definitions of pain terms. Seattle: IASP Press; 1994.

3. Pertoldi S, Di Benedetto P. Shoulder-hand syndrome after stroke: a complex regional pain syndrome. Eura
Medicophys 2005;41:283-92.

4. Tepperman PS, Greyson ND, Hilbert L, Jimenez J, Williams JI. Reflex sympathetic dystrophy in hemiplegia. Arch Phys Med Rehabil 1984;65:442-7.

5. Cheng PT, Hong CZ. Prediction of reflex sympathetic dystrophy in hemiplegic patients by electromyographic study. Stroke 1995;26:2277-80.

6. Daviet JC, Preux PM, Salle JY, Lebreton F, Munoz M, Dudognon $\mathrm{P}$, et al. Clinical factors in the prognosis of complex regional pain syndrome type I after stroke: a prospective study. Am J Phys Med Rehabil 2002;81:34-9.

7. Marinus J, Moseley GL, Birklein F, Baron R, Maihofner C, Kingery WS, et al. Clinical features and pathophysiology of complex regional pain syndrome. Lancet Neurol 2011;10:637-48.

8. Wyatt LH, Ferrance RJ. The musculoskeletal effects of diabetes mellitus. J Can Chiropr Assoc 2006;50:43-50.

9. Pickup JC, Crook MA. Is type II diabetes mellitus a disease of the innate immune system? Diabetologia 1998;41:1241-8.

10. Malkani S, Mordes JP. Implications of using hemoglobin AlC for diagnosing diabetes mellitus. Am J Med 2011;124:395-401.

11. Graf RJ, Halter JB, Pfeifer MA, Halar E, Brozovich F, Porte D Jr. Glycemic control and nerve conduction abnormalities in non-insulin-dependent diabetic subjects. Ann Intern Med 1981;94:307-11.

12. Marshall AT, Crisp AJ. Reflex sympathetic dystrophy. Rheumatology (Oxford) 2000;39:692-5.

13. Kim RP. The musculoskeletal complications of diabetes. Curr Diab Rep 2002;2:49-52.

14. Harden RN, Bruehl S, Stanton-Hicks M, Wilson PR. Proposed new diagnostic criteria for complex regional pain syndrome. Pain Med 2007;8:326-31.

15. Stanton-Hicks MD, Burton AW, Bruehl SP, Carr DB, Harden RN, Hassenbusch SJ, et al. An updated interdisciplinary clinical pathway for CRPS: report of an expert panel. Pain Pract 2002;2:1-16.

16. Calder JS, Holten I, McAllister RM. Evidence for immune system involvement in reflex sympathetic dystrophy. J Hand Surg Br 1998;23:147-50.

17. van der Laan L, Goris RJ. Reflex sympathetic dystrophy: an exaggerated regional inflammatory response? Hand Clin 1997;13:373-85.

18. Holzer P. Neurogenic vasodilatation and plasma leakage in the skin. Gen Pharmacol 1998;30:5-11. 
19. Birklein F, Schmelz M, Schifter S, Weber M. The important role of neuropeptides in complex regional pain syndrome. Neurology 2001;57:2179-84.

20. Schinkel C, Gaertner A, Zaspel J, Zedler S, Faist E, Schuermann M. Inflammatory mediators are altered in the acute phase of posttraumatic complex regional pain syndrome. Clin J Pain 2006;22:235-9.

21. Huygen FJ, Ramdhani N, van Toorenenbergen A, Klein J, Zijlstra FJ. Mast cells are involved in inflammatory reactions during Complex Regional Pain Syndrome type 1. Immunol Lett 2004;91:147-54.

22. Groeneweg JG, Huygen FJ, Heijmans-Antonissen C, Niehof S, Zijlstra FJ. Increased endothelin-1 and diminished nitric oxide levels in blister fluids of patients with intermediate cold type complex regional pain syndrome type 1. BMC Musculoskelet Disord 2006; 7:91.

23. Uceyler N, Eberle T, Rolke R, Birklein F, Sommer C. Differential expression patterns of cytokines in complex regional pain syndrome. Pain 2007;132:195-205.

24. Wesseldijk F, Huygen FJ, Heijmans-Antonissen C, Niehof SP, Zijlstra FJ. Six years follow-up of the levels of TNF-alpha and IL-6 in patients with complex regional pain syndrome type 1 . Mediators Inflamm 2008;2008:469439.

25. Parkitny L, McAuley JH, Di Pietro F, Stanton TR, O'Connell NE, Marinus J, et al. Inflammation in complex regional pain syndrome: a systematic review and meta-analysis. Neurology 2013;80:106-17.

26. Pickup JC. Inflammation and activated innate immunity in the pathogenesis of type 2 diabetes. Diabetes Care 2004;27:813-23.

27. Crook MA, Tutt P, Pickup JC. Elevated serum sialic acid concentration in NIDDM and its relationship to blood pressure and retinopathy. Diabetes Care
1993;16:57-60.

28. Mirza S, Hossain M, Mathews C, Martinez P, Pino P, Gay JL, et al. Type 2-diabetes is associated with elevated levels of TNF-alpha, IL-6 and adiponectin and low levels of leptin in a population of Mexican Americans: a cross-sectional study. Cytokine 2012;57:136-42.

29. Alexandraki KI, Piperi C, Ziakas PD, Apostolopoulos NV, Makrilakis K, Syriou V, et al. Cytokine secretion in long-standing diabetes mellitus type 1 and 2: associations with low-grade systemic inflammation. J Clin Immunol 2008;28:314-21.

30. Bastard JP, Pieroni L, Hainque B. Relationship between plasma plasminogen activator inhibitor 1 and insulin resistance. Diabetes Metab Res Rev 2000;16: 192-201.

31. Donath MY, Shoelson SE. Type 2 diabetes as an inflammatory disease. Nat Rev Immunol 2011;11:98-107.

32. Pickup JC, Chusney GD, Thomas SM, Burt D. Plasma interleukin-6, tumour necrosis factor alpha and blood cytokine production in type 2 diabetes. Life Sci 2000; 67:291-300

33. Dandona P, Aljada A, Chaudhuri A, Bandyopadhyay A. The potential influence of inflammation and insulin resistance on the pathogenesis and treatment of atherosclerosis-related complications in type 2 diabetes. J Clin Endocrinol Metab 2003;88:2422-9.

34. Veldman PH, Reynen HM, Arntz IE, Goris RJ. Signs and symptoms of reflex sympathetic dystrophy: prospective study of 829 patients. Lancet 1993;342:1012-6.

35. Kozin F. Reflex sympathetic dystrophy syndrome: a review. Clin Exp Rheumatol 1992;10:401-9.

36. Schwartzman RJ, McLellan TL. Reflex sympathetic dystrophy: a review. Arch Neurol 1987;44:555-61.

37. Shelton RM, Lewis CW. Reflex sympathetic dystrophy: a review. J Am Acad Dermatol 1990;22:513-20. 